\title{
Lymphogranuloma venereum: diagnostic and treatment challenges
}

This article was published in the following Dove Press journal:

Infection and Drug Resistance

27 March 2015

Number of times this article has been viewed

\author{
Romana Ceovic' \\ Sandra Jerkovic Gulin² \\ 'Department of Dermatology and \\ Venereology, University Hospital \\ Center Zagreb and School \\ of Medicine, Zagreb, Croatia; \\ ${ }^{2}$ Department of Dermatology and \\ Venereology, General Hospital Sibenik, \\ Sibenik, Croatia
}

\begin{abstract}
Lymphogranuloma venereum is a sexually transmitted disease caused by L1, L2, and L3 serovars of Chlamydia trachomatis. In the last 10 years outbreaks have appeared in North America, Europe, and Australia in the form of proctitis among men who have sex with men. Three stages of disease have been described. The disease in primary stage may go undetected when only a painless papule, pustule, or ulceration appears. The diagnosis is difficult to establish on clinical grounds alone and frequently relies upon either serologic testing, culture, or more recently, nucleic acid amplification testing of direct specimens. A proper treatment regimen cures the infection and prevents further damage to tissues. Lymphogranuloma venereum causes potentially severe infections with possibly irreversible sequels if adequate treatment is not begun promptly. Early and accurate diagnosis is essential. Doxycycline is the drug of choice. Pregnant and lactating women should be treated with erythromycin or azithromycin. Patient must be followed up during the treatment, until disease signs and symptoms have resolved. Repeated testing for syphilis, hepatitis B and C, and HIV to detect early infection should be performed.
\end{abstract}

Keywords: sexually transmitted disease, Chlamydia trachomatis, early and accurate diagnosis

\section{Introduction}

Lymphogranuloma venereum (LGV) is a sexually transmitted disease (STD) caused by L1, L2, and L3 serovars of Chlamydia trachomatis that primarily infects the lymphatics and can be transmitted through unprotected vaginal, anal, or oral sexual contact. C. trachomatis is the most common cause of bacterial STDs in both men and women. ${ }^{1}$ C. trachomatis is an obligate intracellular gram-negative bacterium that during its developmental cycle alternates between two forms: the infectious elementary body (EB) and the noninfectious replicating form, the reticulate body. The attachment process of the elementary body to a host cell is the event most crucial to a successful infection. Elementary bodies attach to columnar epithelial cells followed by endocytosis and inhibition of lysosomal fusion. A number of chlamydial ligands have been identified and characterized. These include the major outer membrane protein (MOMP) as well as the cysteine-rich $\mathrm{OmcB}(\mathrm{Omp} 2)$ protein, hsp70, the polymorphic outer membrane proteins, and the thermolabile $34-\mathrm{kDa}$ membrane protein. In addition to these proposed ligands, there is a considerable amount of experimental evidence to suggest that the glycosaminoglycan, heparan sulfate, is involved in the chlamydial attachment-infectivity process. C. trachomatis does not produce heparan sulfate. Heparan sulfate acts as a host cell receptor for MOMP. ${ }^{2}$ The disease was described in 1833 by Wallace, but it was defined as a clinical and pathological entity in 1913 by Durand, Nicolas, and Favre. 
LGV is a subtype of genital ulcer diseases that includes other STDs such as Herpes simplex virus-2 (HSV-2), syphilis, and chancroid. LGV synonyms include lymphopathia venerea, tropical bubo, climatic bubo, strumous bubo, poradenitis inguinales, Durand-Nicolas-Favre disease, and lymphogranuloma inguinale. LGV is endemic in tropical and subtropical areas of the world (certain areas of Africa, Southeast Asia, India, the Caribbean, and South America). The incidence has been low in developed world, but in the last 10 years outbreaks have appeared in North America, Europe, and Australia in the form of proctitis among men who have sex with men (MSM). ${ }^{1,3-5}$ Three stages of disease have been described. The disease in primary stage may go undetected when only a painless papule, pustule, or ulceration appears. ${ }^{6}$ The diagnosis is difficult to establish on clinical grounds alone and frequently relies upon either serologic testing, culture, or more recently, nucleic acid amplification testing (NAAT) of direct specimens. ${ }^{7-9}$ LGV in MSM is associated with a high rate of coinfection with gonorrhea, syphilis, Herpes simplex, hepatitis C, and/or HIV coinfection. When LGV is suspected, diagnostic tests for other potentially coexisting STDs must be performed. Differential diagnoses for LGV include cat scratch disease, chancroid, syphilis, HSV-2, and granuloma inguinale.

\section{Epidemiology}

LGV probably affects both sexes equally, although it is more commonly reported in men because early manifestations of LGV are more apparent in men. Men typically present with the acute form of the disease, whereas women often present when they develop complications from later stages of the disease. LGV may appear at any age, but the highest incidence is between 15 and 40 years (sexually active population). Most cases in Europe and North America have been identified among white, frequently HIV-positive MSM patients presenting with proctitis. Since 2003, there have been a series of LGV outbreaks reported across Europe. ${ }^{10-13}$ Since formal surveillance was launched in 2004, the United Kingdom has seen the highest number of confirmed MSM cases globally. ${ }^{13}$ Between April 2003 and June 2012, more than 2,000 cases of LGV had been confirmed in the United Kingdom. ${ }^{12}$ A large increase in diagnosed cases occurred in late 2009, peaking at 150 cases per quarter in mid-2010; since then, UK rates have remained steady at approximately 80 cases per quarter until 2012. Seventy-seven percent of cases have been diagnosed in London, Brighton, and Manchester. In one report from the United Kingdom (outbreak of 327 new cases of LGV), $76 \%$ MSM were also HIV positive, $39 \%$ had a diagnosis of another STD, and approximately $19 \%$ were also infected with hepatitis $\mathrm{C}$ virus. This is a major public health concern because enhanced shedding of HIV during clinical proctitis could increase the risk of HIV transmission to uninfected men. ${ }^{14}$ Before the outbreaks in MSM, LGV was primarily endemic in heterosexuals in areas of East and West Africa, India, parts of Southeast Asia, and the Caribbean where it is manifested as the classic form of disease with genital ulcers and lymphadenopathy (without proctitis). In these regions, a survey from Madagascar showed that C. trachomatis is not the main cause of genital ulcers. In that survey, $76 \%$ of 196 patients with genital ulcers had chlamydial antibodies, but only $8 \%$ of patients had LGV confirmed by multiplex polymerase chain reaction (PCR). ${ }^{15,16}$

From the beginning of the year 2007 until the end of 2011, 146 cases of LGV were notified in Barcelona. ${ }^{17}$ There are new cases in Finland, ${ }^{18}$ Czech Republic, ${ }^{19}$ and France where the first case of C. trachomatis $\mathrm{L} 2 \mathrm{~b}$ proctitis was described in a woman. ${ }^{20}$ Authors from the Netherlands reported a case study of a female patient with bubonic LGV caused by serovar L2b, which was probably contracted via her bisexual male partner. $^{21}$ There are also complicated cases such as LGV infection mimicking deep-vein thrombosis ${ }^{22}$ and reactive arthritis associated with $\mathrm{LGV}^{23}$

LGV among MSM in Europe is caused in the majority of cases by the C. trachomatis serovar L2b, which shows a high degree of clonal relatedness as found by Multi Locus Sequence Typing in a molecular epidemiological study. This is in contrast to the strains circulating among MSM in the United States, which show more molecular diversity. Based on these findings, it is now speculated that the LGV epidemic among MSM in Europe caused by the L2b variant may have been imported to Europe from the United States by the end of the previous century via the highly internationalized network of sexual contacts among MSM.4,24 The same serotype of $C$. trachomatis was identified in rectal swabs between 1979 and 1985 from patients infected with HIV in San Francisco and between 2000 and 2005 in 92 MSM patients with LGV in Amsterdam. ${ }^{24}$ A small number of cases of $\mathrm{L}$ serovar $\mathrm{LGV}$ have been reported in heterosexuals in the United Kingdom and Europe (including seven women in the United Kingdom since 2004), but these appear linked to bisexual male partners or sexual contact with those returning from endemic regions. ${ }^{13,14}$ Prior to 2003, most cases in Europe were imported via travelers, sailors, and soldiers. ${ }^{4,25}$

In the United States, the true incidence is unknown because national reporting of LGV ended in 1995. Between November 2004 and January 2006, LGV was identified in 
180 people, with 27 people identified as being obtained from homosexual males. A study published in 2011 reporting LGV surveillance data from multiple sites in the United States found that less than $1 \%$ of the samples obtained from rectal swabs of MSM that were positive for C. trachomatis tested positive for $\mathrm{LGV}^{26}$

\section{Pathophysiology}

C. trachomatis is divided into 15 serovars (A, B, Ba, C-K, and L1-L3) based on analysis of the MOMP. Serovars L1-L3 cause LGV. The L2 serovar can be further separated into L2, L2', L2a, or L2b according to minor differences in their component amino acids. LGV is predominantly a disease of the lymphatic tissue. ${ }^{6}$ In contrast to serovars $\mathrm{A}-\mathrm{K}$, which remain confined to the mucosa, the LGV serovars $C$. trachomatis induce a lymphoproliferative reaction, it gains entrance through skin breaks and abrasions or it crosses the epithelial cells of mucous membranes. LGV serovars and other strains of $C$. trachomatis appear to bind to epithelial cells via heparan sulfate receptors ${ }^{27}$ and then it travels via lymphatics to multiply within mononuclear phagocytes in regional lymph nodes. After lymphangitis, areas of necrosis occur within the nodes, followed by the formation of abscess. ${ }^{27}$ In one study of 12 patients, lymph node macrophages contained organisms that stained black with Warthin-Starry stain, ${ }^{28}$ the organisms were clustered within vacuoles and both reticulate and elementary bodies were visible by electron microscopy. PCR testing of the lymph nodes for LGV serovars of C. trachomatis was positive in 9/12 cases. The pathologic findings are compatible with LGV or Bartonella henselae (ie, "cat scratch" disease), but are not diagnostic of either entity. ${ }^{29}$ The lymph node reaction may take several weeks to develop and can result in substantial inflammation and subsequent fibrosis. ${ }^{6}$ In a small number of cases, dissemination and systemic disease can occur. Neither the degree of infectiousness nor the reservoir of disease has been accurately defined, but heterosexual transmission has been attributed largely to asymptomatic female carriers and in the MSM population; asymptomatic rectal infection and/or penile infection is the likely source of onward transmission. ${ }^{30}$

\section{Clinical features}

\section{First stage (primary LGV)}

The incubation period lasts 3-30 days, after which a primary lesion occurs in the form of a small painless papule, pustule, nodule, shallow erosion, or herpetiform ulcer (Table 1). The initial lesions may be differentiated from the more common herpetic lesions by the lack of pain associated with the lesion. Differentiation from a syphilitic chancre requires serologic testing. The primary lesion of LGV is most commonly located

Table I Clinical features of lymphogranuloma venereum

\begin{tabular}{|c|c|}
\hline Men & Women \\
\hline First stage & First stage \\
\hline $\begin{array}{l}\text { - Painless papule/pustule/nodule/erosion/ulcer on penis/anus/* } \\
\text { lip and oral cavity (tonsil) }\end{array}$ & $\begin{array}{l}\text { - Painless papule/pustule/nodule/erosion/ulcer on vulva/posterior vaginal } \\
\text { wall/cervix/anus/* lip and oral cavity }\end{array}$ \\
\hline $\begin{array}{l}\text { - Proctitis (symptoms: rectal pain, anorectal bleeding, mucoid } \\
\text { and/or hemopurulent rectal discharge, tenesmus, constipation) }\end{array}$ & $\begin{array}{l}\text { - Proctitis (symptoms: rectal pain, anorectal bleeding, mucoid and/or } \\
\text { hemopurulent rectal discharge, tenesmus, constipation) }\end{array}$ \\
\hline Second stage & Second stage \\
\hline - Lymphadenitis & - Lymphadenitis \\
\hline - Intra-abdominal or retroperitoneal lymphadenopathy & - Intra-abdominal or retroperitoneal lymphadenopathy \\
\hline $\begin{array}{l}\text { - Inguino and/or femoral lymph adenopathy (typically unilateral, } \\
\text { heterosexuals) }\end{array}$ & $\begin{array}{l}\text { - Inguino and/or femoral lymph adenopathy (typically unilateral, only } 20 \% \\
\text { of women) }\end{array}$ \\
\hline $\begin{array}{l}\text { - Bubo formation (fluctuant and suppurative lymph nodes that } \\
\text { may rupture) } \\
\text { - Fever/arthritis/pneumonitis/perihepatitis/abnormal hepatic } \\
\text { enzymes (systemic spread) }\end{array}$ & $\begin{array}{l}\text { - Bubo formation (fluctuant and suppurative lymph nodes that may rupture) } \\
\text { - Fever/arthritis/pneumonitis/perihepatitis/abnormal hepatic enzymes } \\
\text { (systemic spread) }\end{array}$ \\
\hline Third stage & Third stage \\
\hline - Genito-anorectal syndrome (more often in women) & - Genito-anorectal syndrome (more often in women) \\
\hline - Chronic proctitis & - Chronic proctitis \\
\hline - Fistulae & - Fistulae \\
\hline - Strictures & - Strictures \\
\hline - Stenosis of rectum & - Stenosis of rectum \\
\hline - Genital lymphedema (elephantiasis, “saxophone penis”) & - Genital lymphedema (elephantiasis) \\
\hline \multirow[t]{2}{*}{ - "Lymphorroids" } & - "Lymphorroids" \\
\hline & - Scarring of vulva (esthiomene) \\
\hline
\end{tabular}

Note: *Rare cases. 
on the coronal sulcus of men and on the posterior vaginal wall, fourchette (known as the frenulum of labia minora/ posterior commissure of the labia minora) or vulva and on the cervix of women. The lesion usually heals within 1 week and may go unnoticed in the urethra, vagina, or rectum. Mucopurulent discharge from urethra, cervix, or rectum may be present regarding the inoculation site. Some ulcers in the recent MSM outbreak have been described as indurated and of variable tenderness; their duration has been as long as several weeks. ${ }^{31}$ Extra-genital lesions have been reported such as ulcers and fissures in the perianal area in MSM, ${ }^{32}$ the lip or oral cavity (tonsil), and extra-genital lymph nodes. ${ }^{33,34}$

The new clinical picture is mostly seen among the MSM. Hemorrhagic proctitis in MSM is the primary manifestation of infection following direct transmission to the rectal mucosa. It might also occur in women with rectal exposure. ${ }^{35}$ In the recent outbreaks of LGV in MSM in Western Europe, approximately $96 \%$ of all cases presented with proctitis; symptoms included rectal pain, anorectal bleeding, mucoid and/or hemopurulent rectal discharge, tenesmus, constipation, and other symptoms of lower gastrointestinal inflammation. However, patients may present to gastroenterologists or colorectal surgeons for persisting symptoms. ${ }^{36}$ Endoscopic features are nonspecific, with a wide range of differential diagnoses including Crohn's disease, lymphoma, anorectal carcinoma, and other sexually transmitted ulcerative infections (eg, syphilis, herpes). ${ }^{37,38} \mathrm{LGV}$ proctitis mimics chronic inflammatory bowel disease, both clinically and in the pathological substrate. These cases may present with an incomplete or undisclosed history of proctosigmoiditis, without the characteristic adenopathy syndrome. During the initial evaluation and colonoscopy, there is a strong clinical and endoscopic suspicion of inflammatory bowel disease by virtue of presentation and endoscopic and histological findings. The diagnosis of IBD is subsequently modified to LGV proctosigmoiditis when one or more of the following transpire: 1) there is a failure of response to inflammatory bowel disease therapy; 2) additional components of history are identified (MSM/travel); 3 ) initially performed chlamydia antibody test shows seroconversion in the follow-up sample; and 4) response to antibiotics effective against chlamydia. ${ }^{39}$ Some patients reported systemic symptoms (fever and malaise). Genital ulcers and inguinal symptoms were less common. ${ }^{36}$

Several cases of pharyngeal MSM LGV infection have been reported recently. LGV serovars can cause symptomatic ulceration and pharyngitis but also asymptomatic carriage at this site. ${ }^{33}$

\section{Secondary lesions (secondary LGV)}

Secondary LGV begins within 2-6 weeks after the onset of primary lesion. Depending on the site of inoculation, LGV can cause inguinal syndrome (after primary lesion of the anterior vulva, penis, or urethra) or anorectal syndrome (usually after primary lesion of the posterior vulva, vagina, or anus).

Inguinal syndrome presents with painful inflammation of the inguinal (superficial and deep) lymph nodes and occurs mostly in men (occurs in only $20 \%$ of women with LGV). It is the most common clinical manifestation of genital LGV among heterosexuals. In two-thirds of cases, this produces unilateral enlargement, inflammation, suppuration, and abscesses. The disease process may involve one or many lymph nodes, and if adjacent to one another, they may coalesce. The central areas of such lymph nodes may then undergo necrosis. Fluctuant and suppurative lymph nodes then develop, causing the classic "bubo" of LGV. These "buboes" may rupture in one-third of patients, which may lead to sinus tract formation. In other cases, they may develop into hard, nonsuppurative masses. When both inguinal and femoral lymph nodes are involved, they can be separated by the inguinal (Poupart's) ligament, "Groove sign". This sign is pathognomonic of LGV, but occurs in only $15 \%-20 \%$ of cases. $^{40}$

Women often have primary involvement of upper vagina, cervix, or posterior urethra; however, if they are receptive to anal sex they may have primary involvement of the rectum. These regions drain to the deep iliac or perirectal nodes and cause intra-abdominal or retroperitoneal lymphadenopathy that may lead to symptoms of lower abdominal pain or lowback pain. ${ }^{41}$

The systemic spread of LGV C. trachomatis may be associated with low-grade fever, chills, malaise, myalgias, and arthralgias. In addition, systemic spread occasionally results in arthritis, pneumonitis, abnormal hepatic enzymes, and perihepatitis. Rare systemic complications include cardiac involvement, aseptic meningitis, and ocular inflammatory disease. ${ }^{40}$ Reactive arthritis in MSM following LGV proctitis has been reported in several cases in recent years. ${ }^{42}$

In the rare pharyngeal syndrome affecting the mouth and throat, cervical lymphadenopathy and buboes can occur. ${ }^{18}$

\section{Tertiary-stage/genito-anorectal syndrome/anogenitorectal syndrome/third-stage LGV}

This stage manifests predominantly in women, but also in homosexual men, because of the location of the 
involved lymphatics. It is characterized by a chronic inflammatory response and the destruction of tissue, which is followed by the formation of perirectal abscess, fistulas, strictures, and stenosis of rectum. Lymphorroids are hemorrhoid-like swellings of obstructed perirectal, and intestinal lymphatics may also occur. If it is not treated, chronic progressive lymphangitis leads to chronic edema and sclerosing fibrosis. This results in strictures and fistulas that can cause elephantiasis of the genitals, esthiomene (chronic ulcerative disease of vulva leading to disfiguring fibrosis and scarring), and frozen pelvis syndrome., ${ }^{9,41}$ Penile and scrotal edema and distortion have been termed "saxophone penis". ${ }^{43}$ LGV proctitis can lead not only to rectal stricture but also to development of mega colon. ${ }^{44}$ Within the current MSM outbreak, tertiary complications of anorectal LGV such as strictures and fistulas have been observed rarely. ${ }^{45}$

Finally, regarding clinical features, it has to be noted that in the present LGV epidemic among MSM, UK cohorts showed almost all LGV to be symptomatic, ${ }^{3,14}$ but Dutch studies had a significant proportion of asymptomatic infection detected. ${ }^{46,47}$ In a study conducted in the Netherlands that included LGV among MSM diagnosed in 2003-2004, only one patient, with onset of illness in April 2003, had symptoms usually associated with LGV (ie, inguinal adenopathy and a painful genital ulcer); all other patients had gastrointestinal symptoms (eg, bloody proctitis with a purulent or mucous anal discharge and constipation). ${ }^{45}$

\section{Diagnosis}

Modern techniques now rely on nucleic acid amplification tests (NAATs) in well-equipped laboratories. ${ }^{35}$ The assays have high sensitivity and specificity. C. trachomatis is an intracellular organism, so samples should contain cellular material. For the detection of LGV serovars of C. trachomatis, different DNA samples can be used: 1) primary anogenital lesion swab (ulcer base exudate), 2) rectal mucosa swab (when anorectal LGV is suspected), or 3) enlarged or fluctuant lymph nodes or buboes aspirate (when inguinal LGV is suspected). ${ }^{9,41}$ After topical disinfection, a 21-gauge needle should be inserted into the lymph node through healthy adjacent tissue and the pus aspirated into a syringe; a small volume $(<0.5 \mathrm{~mL})$ of saline solution may be injected and re-aspirated for nonfluctuant nodes. Urethral swab or first-catch urine specimen can be used as a sample when urethritis and/or inguinal lymphadenopathy is present and LGV is suspected as the cause. Urine specimen usually shows negative PCR results in case of anorectal manifestation of $\mathrm{LGV}^{35}$ A two-step procedure is usually followed. The first step includes $C$. trachomatis NAAT test (test only confirms presence of $C$. trachomatis, and does not allow serogroup identification). NAATs are not approved for testing samples from extra-genital sites, but studies have demonstrated high sensitivity and specificity in rectal chlamydial infections. ${ }^{9,41,47-49}$ C. trachomatis NAATs can be performed using one of three methods: PCR, strand displacement amplification, or transcription-mediated amplification. The second step is performed only if the first step test detects $C$. trachomatis in the sample. The second step diagnostic test is LGV biovar-specific DNA NAAT from the same sample used in first step test. Two tests for the second step are available: a real-time PCR-based test (detects all C. trachomatis LGV biovar strains) $)^{9,41,50}$ and a real-time quadriplex PCR-based assay. Both PCR techniques are reliable; the assay correctly identified $100 \%$ of non-LGV chlamydial specimens, $100 \%$ with no chlamydial infection, and $96.36 \%$ LGV specimens. ${ }^{47,51}$

For patients with genital disease, genital and lymph node specimens (lesion swabs and bubo aspirate) may be tested for $C$. trachomatis by 1) culture or 2) direct immunofluorescence (relatively insensitive). It is not always possible to culture the organism. Culture at primary stage is not often possible because the primary lesion often goes unnoticed. Culture on cyclohexamide-treated McCoy cells has a sensitivity of $75 \%-85 \%$ at best when the specimen is from LGV-suspected lesions and less for bubo aspirates. ${ }^{35,52}$ This method requires a lot of time, work, and money, and the availability is questionable.

If NAATs are not available, then Chlamydia genus-specific serological assays can be used. Four techniques are available: 1) the complement fixation, 2) the single L-type immunofluorescence test, 3) the micro-immunofluorescence test, and 4) anti-MOMP IgA assay (UK). With appropriate clinical presentation, a complement fixation antibody titer of higher than 1:64 is considered diagnostic. Titers that are greater than 1:256 are highly suggestive. In addition, a four-fold increase in the complement fixation titer of blood samples taken 2 weeks apart is indicative. ${ }^{2} \mathrm{~A}$ four-fold rise in antibody or single-point titers of $>1 / 64$ and $>128$ for the micro-immunofluorescence test has been considered positive. ${ }^{35,53,54}$ When clinical features are suggestive of LGV, high Ig anti-MOMP antibodies titer supports the diagnosis. Recent study from the Netherlands showed the anti-MOMP IgA serological assay to be the most useful for rectal LGV infection. The test has 75.5\% sensitivity and $74.3 \%$ specificity in asymptomatic MSM with rectal C. trachomatis, and $85.7 \%$ sensitivity and $84.2 \%$ specificity in symptomatic MSM. The IgA anti-MOMP assay can 
identify a considerable proportion of the (asymptomatic) anal LGV infections correctly. Yet, biovar L-specific NAAT are still the preferred diagnostic tests in clinical settings. ${ }^{35,55,56}$ It is important to stress that neither a low titer excludes LGV nor does a high titer in patient without symptoms confirm LGV. . $^{48,49}$

The identification of rectal polymorphonuclear leucocytes from rectal swabs is predictive of LGV proctitis, especially in HIV-positive MSM. In a study of 87 MSM with confirmed LGV, majority of samples (Gram-stained anorectal swabs) had more than 10 white blood cells (WBCs) per high-power field. 35,47

Histology of the lymph nodes is not specific: follicular hyperplasia, abscesses, cryptitis, and crypt abscesses without distortion of crypt architecture (last two were the most common findings in 12 anorectal biopsies from LGV in MSM). ${ }^{30,49}$

\section{Management}

A proper treatment regimen cures the infection and prevents further damage to tissues. LGV causes potentially severe infections with possibly irreversible sequels if adequate treatment is not begun promptly. Early and accurate diagnosis is essential. ${ }^{4,94}$ The management of the ongoing epidemic LGV in industrialized Western countries caused by the C. trachomatis variant L2b still needs improvements in diagnosis, therapy, and prevention. Therefore, the rapid $C$. trachomatis variant L2b-specific PCR has been developed to circumvent laborious ompA gene sequencing. ${ }^{57}$ C. trachomatis should be treated with antibacterial drugs reaching high intracellular concentrations. In general, intracellular-acting agents such as doxycycline, erythromycin, and azithromycin and certain quinolones are advised. ${ }^{58}$ Doxycycline is the drug of choice for patients who are not pregnant. ${ }^{9,35,41}$ Pregnant and lactating women should be treated with erythromycin or azithromycin. Only one case of clinical failure with extended doxycycline therapy has been reported in an HIV-negative MSM with anorectal LGV. He subsequently responded to treatment with moxifloxacin $400 \mathrm{mg}$ daily for 10 days; no isolate was available for resistance testing. ${ }^{35,59}$ Three MSMs who developed inguinal LGV failed the recommended 21-day doxycycline treatment. A recent paper suggests that inguinal LGV may require prolonged courses of doxycycline, exceeding the currently advised 21 -day regimen. ${ }^{3}$ Current STD treatment guidelines for MSM in the United States recommend treatment of rectal chlamydia with a single 1-g dose of azithromycin, but there are increasing concerns about its effectiveness with treatment failures reported. ${ }^{59-61} \mathrm{~A}$ recent retrospective study conducted in the United States compared azithromycin and doxycycline for the treatment of rectal chlamydial infection; persistent/recurrent infection was higher among men treated with azithromycin (22\%) compared with doxycycline (8\%). These data suggest that doxycycline may be more effective than azythromycin in the treatment of rectal chlamydial infections. ${ }^{61}$ Factors that may be contributing to treatment failure for rectal chlamydia include: pharmacokinetic properties of azithromycin and doxycycline in rectal tissue, the ability of chlamydia to transform into a persistent state that is less responsive to antimicrobial therapy, the impact of the rectal microbiome on chlamydia, and heterotypic resistance. ${ }^{60}$ Recommended treatment regimens for LGV are listed in Table 2. As adjunctive therapy, the aspiration of fluctuant buboes is recommended for pain relief and prevention of rupture or chronic sinus formation, in contrast to surgical incision of buboes due to potential complications. The pharynx is a reservoir for chlamydia and LGV and may play a role in ongoing transmission. Although spontaneous clearance may occur in untreated patients with pharyngeal chlamydia, in high-risk STD clinic patients, testing the pharynx for chlamydia should be considered. ${ }^{56}$

A recent study suggests that HIV seropositivity was the strongest risk factor for LGV and that proctoscopic findings and elevated WBC counts in anorectal smear specimens were the only clinically relevant predictors for LGV infection. For all MSM reporting receptive anorectal intercourse, rectal chlamydia screening is recommended. If chlamydia test results are not available, for MSM reporting receptive anorectal intercourse who have proctitis noted by proctoscopic examination and a WBC count of $>10$ cells/ high-power field in an anorectal Gram stain specimen or who have proctitis noted by proctoscopic examination and HIV seropositivity, treatment with doxycycline (100 mg twice per day) is advised until chlamydia test results are available, with a minimum duration of treatment of 7 days. If the anorectal chlamydia test result is negative, no treatment should be administered or doxycycline treatment should be stopped after a minimum of 7 days. If the anorectal chlamydia test result is positive and LGV testing is available, doxycycline treatment (100 mg twice per day) should be started or continued until LGV is rejected. A 7-day course of doxycycline is effective for treatment of a non-LGV chlamydia. Therapy should be continued until 21 days after confirmation of LGV. If the anorectal chlamydia test result is positive and if $\mathrm{LGV}$ testing is unavailable, doxycycline treatment (100 mg twice per day for up to 21 days) should be started or continued for MSM who meet one of the following criteria: proctitis 
Table 2 Recommended treatment regimens for lymphogranuloma venereum

\begin{tabular}{|c|c|c|c|}
\hline Drug & Regimen & Mechanism/possible side effects & Comment \\
\hline Doxycycline & $\begin{array}{l}100 \mathrm{mg} \text { twice daily } \\
\text { for } 21 \text { days, orally }\end{array}$ & $\begin{array}{l}\text { - Inhibits protein synthesis by binding to } 30 \mathrm{~S} \\
\text { ribosomal subunits of susceptible bacteria } \\
\text { - Dyspepsia; nausea; diarrhea; photosensitivity; } \\
\text { darkening of skin, nails, eyes, teeth, gums, or } \\
\text { scars; esophageal ulceration; Fanconi syndrome } \\
\text { (nephrotoxicity); steatosis (hepatotoxicity); } \\
\text { headache and vision problems (secondary } \\
\text { intracranial hypertension-pseudotumor cerebri) }\end{array}$ & $\begin{array}{l}\text { - First choice, recommended by Centers } \\
\text { for Disease Control } \\
\text { - Contraindicated in pregnancy and } \\
\text { breastfeeding } \\
\text { - Antacids that contain aluminum, calcium, } \\
\text { or magnesium or any product that } \\
\text { contains iron such as vitamin or mineral } \\
\text { supplements should not be taken }\end{array}$ \\
\hline Erythromycin & $\begin{array}{l}500 \mathrm{mg} \text { four times daily } \\
\text { for } 21 \text { days, orally }\end{array}$ & $\begin{array}{l}\text { - Inhibits bacterial growth by blocking dissociation } \\
\text { of peptidyl tRNA from ribosomes } \\
\text { - Diarrhea, stomach pain, nausea, vomiting } \\
\text { - } 60,67\end{array}$ & $\begin{array}{l}\text { Second choice; recommended by Centers } \\
\text { for Disease Control }\end{array}$ \\
\hline Azithromycin & $\begin{array}{l}\text { I g stat, orally } \\
\text { Ig weekly for } 3 \text { weeks, } \\
\text { orally }\end{array}$ & $\begin{array}{l}\text { - Inhibits bacterial protein synthesis by binding } \\
\text { to the } 50 \text { S ribosomal subunit of the bacterial } \\
70 \text { S ribosome } \\
\text { - The same as for erythromycin }\end{array}$ & $\begin{array}{l}\text { Should be considered as second choice, but } \\
\text { evidence is lacking to recommend this drug } \\
\text { currently }\end{array}$ \\
\hline Tetracycline & $\begin{array}{l}500 \mathrm{mg} \text { four times daily } \\
\text { for } 21 \text { days, orally }\end{array}$ & $\begin{array}{l}\text { - The same as for doxycycline } \\
\text { - The same side effects listed earlier for doxycycline }\end{array}$ & The same as for doxycycline \\
\hline Minocycline & $\begin{array}{l}300 \mathrm{mg} \text { loading dose, } \\
\text { followed by } 200 \mathrm{mg} \text { twice } \\
\text { daily for } 2 \mathrm{I} \text { days, orally }\end{array}$ & $\begin{array}{l}\text { - The same as for doxycycline } \\
\text { - Vertigo, dizziness, ataxia, tinnitus, and the } \\
\text { side effects listed earlier for doxycycline }{ }^{68,69}\end{array}$ & The same as for doxycycline \\
\hline Moxifloxacin & $\begin{array}{l}400 \mathrm{mg} \text { once daily for } \\
21 \text { days, orally }\end{array}$ & $\begin{array}{l}\text { - Blocks DNA gyrase enzyme (it is responsible } \\
\text { for production and repair of bacterial DNA) } \\
\text { and it leads to bacteria death } \\
\text { - Nausea, dizziness, diarrhea, QT prolongation, } \\
\text { and photosensitivity }\end{array}$ & $\begin{array}{l}\text { - Administration should be separated from } \\
\text { aluminum- and magnesium-containing } \\
\text { antacids, sucralfate, and multivitamins } \\
\text { because they can lower absorption of } \\
\text { moxifloxacin and reduce its effectiveness } \\
\text { - Should be used with caution with warfarin } \\
\text { (increases risk for bleeding) and sotalol } \\
\text { (abnormal heart rhythm) }\end{array}$ \\
\hline
\end{tabular}

noted during initial proctoscopic examination, $>10 \mathrm{WBCs} /$ high-power field in the initial Gram-stained anorectal smear specimen, or HIV seropositivity. ${ }^{9}$

Persons who have had sexual contact with a patient who has LGV within 4 weeks before the onset of the patient's symptoms, or the last 3 months if asymptomatic LGV is detected, must be tested for $C$. trachomatis/LGV and start treatment (doxycycline $100 \mathrm{mg}$ twice daily for 21 day). Patients must be followed up during the treatment, until disease signs and symptoms have resolved. Repeated testing for syphilis, hepatitis B and C, and HIV to detect early infection should be performed. A test of cure for LGV is not considered necessary if the recommended 21-day course of doxycycline is completed. ${ }^{9,41}$

\section{Health promotion/prevention}

The outbreaks of LGV among MSM in developed countries support the need for careful screening of these patients. A routine screening for rectal chlamydia is recommended in asymptomatic men at risk, as this may represent an important reservoir for the onward transmission of infection. Treatment of this group of patients is essential in the attempt to eradicate the disease. Patients should get information about safer sex behavior. Condom use may reduce the risk of LGV transmission, but uncovered ulcerated areas remain a problem. With early and accurate diagnosis and appropriate antibiotic therapy, the prognosis is excellent, but reinfection and relapses may occur. ${ }^{70}$

\section{Disclosure}

The authors have no conflict of interest related to this paper.

\section{References}

1. Beigi RH. Lymphogranuloma venereum. In: Beigi RH, editor. Sexually Transmitted Diseases. West Sussex, UK: John Wiley \& Sons, LTD; 2012:49-52.

2. Taraktchoglou M, Pacey AA, Turnbull JE, Eley A. Infectivity of Chlamydia trachomatis serovar LGV but not $\mathrm{E}$ is dependent on host cell heparansulfate. Infect Immun. 2001;69(2):968-976.

3. Oud EV, de Vrieze NH, de Meij A, de Vries HJ. Pitfalls in the diagnosis and management of inguinal lymphogranuloma venereum: important lessons from a case series. Sex Transm Infect. 2014;90(4):279-282.

4. de Vries HJ, Zingoni A, Kreuter A, Moi H, White JA. 2013 European guideline on the management of lymphogranuloma venereum. $J$ Eur Acad Dermatol Venereol. 2015;29(1):1-6.

5. de Vrieze NH, de Vries HJ. Lymphogranuloma venereum among men who have sex with men. An epidemiological and clinical review. Expert Rev Anti Infect Ther. 2014;12(6):697-704. 
6. Mabey D, Peeling RW. Lymphogranuloma venereum. Sex Transm Infect. 2002;78(2):90-92.

7. Behets FM, Brathwaite AR, Hylton-Kong T, et al. Genital ulcers: etiology, clinical diagnosis, and associated human immunodeficiency virus infection in Kingston, Jamaica. Clin Infect Dis. 1999;28(5): 1086-1090.

8. Ndinya-Achola JO, Kihara AN, Fisher LD, et al. Presumptive specific clinical diagnosis of genital ulcer disease (GUD) in a primary health care setting in Nairobi. Int J STD AIDS. 1996;7(3):201-205.

9. Van der Bij AK, Spaargaren J, Morré SA, et al. Diagnostic and clinical implications of anorectal lymphogranuloma venereum in men who have sex with men: a retrospective case-control study. Clin Infect Dis. 2006;42(2):186-194.

10. Ward H, Alexander S, Carder C, et al. The prevalence of Lymphogranuloma venereum (LGV) infection in men who have sex with men: results of a multi-centre case finding study. Sex Transm Infect. 2009;85(3): 173-175.

11. Hughes G, Alexander S, Simms I, et al; LGV Incident Group. Lymphogranuloma venereum diagnoses among men who have sex with men in the UK: interpreting a cross-sectional study using an epidemic phase-specific framework. Sex Transm Infect. 2013;89(7):542-547.

12. de Vries HJ, van der Bij AK, Fennema JS, et al. Lymphogranuloma venereum proctitis in men who have sex with men is associated with anal enema use and high-risk behavior. Sex Transm Dis. 2008;35(2): 203-208.

13. Savage EJ, van de Laar MJ, Gallay A, et al; European Surveillance of Sexually Transmitted Infections (ESSTI) network. Lymphogranuloma venereum in Europe, 2003-2008. Euro Surveill. 2009;14(48):19428.

14. Ward H, Martin I, Macdonald N, et al. Lymphogranuloma venereum in the United Kingdom. Clin Infect Dis. 2007;44(1):26-32.

15. Behets FM, Andriamiadana J, Randrianasolo D, et al. Chancroid, primary syphilis, genital herpes, and lymphogranuloma venereum in Antananarivo, Madagascar. J Infect Dis. 1999;180(4):1382-1385.

16. Brathwaite AR, Figueroa JP, Ward E. A comparison of prevalence rates of genital ulcers among persons attending a sexually transmitted disease clinic in Jamaica. West Indian Med J. 1997;46(3):67-71.

17. Vargas-Leguas H, Garcia de Olalla P, Arando M, et al. Lymphogranuloma venereum: a hidden emerging problem, Barcelona 2011. Euro Surveill. 2012;17(2):20057

18. Korhonen S, Hiltunen-Back E, Puolakkainen M. Genotyping of Chlamydia trachomatis in rectal and pharyngeal specimens: identification of LGV genotypes in Finland. Sex Transm Infect. 2012;88:465-469.

19. Vanousova D, Zakoucka H, Jilich D, et al. First detection of Chlamydia trachomatis LGV biovar in the Czech Republic, 2010-2011. Euro Surveill. 2012;17(2):20055.

20. Peuchant O, Baldit C, Le Roy C, et al. First case of Chlamydia trachomatis L2b proctitis in a woman. Clin Microbiol Infect. 2011;17(12): 21-23.

21. Verweij SP, Ouburg S, de Vries H, et al. The first case record of a female patient with bubonic lymphogranuloma venereum (LGV), serovariant L2b. Sex Trans Infect. 2012;88(5):346-347.

22. Kennedy JE, Higgins SP. Complicated lymphogranuloma venereum infection mimicking deep vein thrombosis in an HIV-positive man. Int J STD AIDS. 2012;23(3):219-220.

23. Pendle S, Growers A. Reactive arthritis associated with proctitis due to Chlamydia trachomatis serovar L2b. Sex Transm Dis. 2012;39(1): 79-80.

24. Schachter J. Confirming positive results of nucleic acid amplification tests (NAATs) for Chlamydia trachomatis: all NAATs are not created equal. J Clin Microbiol. 2005;43(3):1372-1373.

25. Basta-Juzbasic A, Ceovic R. Chancroid, lymphogranuloma venereum, granuloma inguinale, genital herpes simplex infection, and molluscum contagiosum. Clin Dermatol. 2014;32(2):290-298.

26. Hardick J, Quinn N, Eshelman S, et al; The HPTN $06^{1}$ Study Team. Multi-site screening for lymphogranuloma venereum (LGV) in the USA. Sex Transm Infect. 2011;87(1):60-64.
27. Chen JC, Stephens RS. Trachoma and LGV biovars of Chlamydia trachomatis share the same glycosaminoglycan-dependent mechanism for infection of eukaryotic cells. Mol Microbiol. 1994;11(3):501-507.

28. Hadfield TL, Lamy Y, Wear DJ. Demonstration of Chlamydia trachomatis in inguinal lymphadenitis of lymphogranuloma venereum: a light microscopy, electron microscopy and polymerase chain reaction study. Mod Pathol. 1995;8(9):924-929.

29. Jones RB, Batteiger BE. Chlamydia trachomatis (trachoma, perinatal infections, lymphogranuloma venereum, and other genital infections). In: Mandell GL, Bennett JE, Dolin R, editors. Principles and Practice of Infectious Diseases. Fifth ed. Philadelphia: Churchill Livingstone; 2000:1989.

30. Jebbari H, Alexander S, Ward H, et al; UK LGV Incident Group. Update on lymphogranuloma venereum in the UK. Sex Transm Infect. 2007;83(4):324-326.

31. Sethi G, Allason-Jones E, Richens J, et al. Lymphogranuloma venereum presenting as genital ulceration and inguinal syndrome in men who have sex with men in London, UK. Sex Transm Infect. 2009;85(3): $165-170$.

32. Singhrao T, Higham E, French P. Lymphogranuloma venereum presenting as perianal ulceration: an emerging clinical presentation? Sex Transm Infect. 2011;87(2):123-124.

33. Dosekun O, Edmonds S, Stockwell S, French P, White JA. Lymphogranuloma venereum detected from pharynx in four London men who have sex with men. Int J STD AIDS. 2013;24(6):495-496.

34. Andrada MT, Dhar JK, Wilde H. Oral lymphogranuloma venereum and cervical lymphadenopathy. Mil Med. 1974;139(2):99-101.

35. White J, O'Farrell N, Daniels D. 2013 UK national guideline for the management of lymphogranuloma venereum. Int J STD AIDS. 2013; 24(8):593-601.

36. Nieuwenhuis RF, Ossewaarde JM, Götz HM, et al. Resurgence of lymphogranuloma venereum in Western Europe: an outbreak of Chlamydia trachomatis serovar L2 proctitis in The Netherlands among men who have sex with men. Clin Infect Dis. 2004;39(7):996-1003.

37. Ahdoot A, Kotler DP, Suh JS, Kutler C, Flamholz R. Lymphogranuloma venereum in human immunodeficiency virus-infected individuals in New York City. J Clin Gastroenterol. 2006;40:385-390.

38. Tinmouth J, Rachlis A, Wesson T, Hsieh E. Lymphogranuloma venereum in North America: case reports and an update for gastroenterologists. Clin Gasteroenterol Hepatol. 2006;4:469-473.

39. Gallegos M, Bradly D, Jakate S, Keshavarzian A. Lymphogranuloma venereum proctosigmoiditis is a mimicker of inflammatory bowel disease. World J Gastroenterol. 2012;18(25):3317-3321.

40. Roest RW, Van der Meijden WI. European guideline for the management of tropical genito-ulcerative diseases. Int J STD AIDS. 2001;12(3): $78-83$.

41. de Vries HJ, Zingoni A, White JA, Ross JD, Kreuter A. 2013 European guideline on the management of proctitis, proctocolitis and enteritis caused by sexually transmissible pathogens. Int J STD AIDS. 2013; 25(7):465-474.

42. Kober C, Richardson D, Bell C, Walker-Bone K. Acute seronegative polyarthritis associated with lymphogranuloma venereum infection in a patient with prevalent HIV infection. Int J STD AIDS. 2011;22(1): $59-60$.

43. Koley S, Mandal RK. Saxophone penis after unilateral inguinal bubo of lymphogranuloma venereum. Indian J Sex Transm Dis. 2013;34(2): 149-151.

44. Pinsk I, Saloojee N, Friedlich M. Lymphogranuloma venereum as a cause of rectal stricture. Can J Surg. 2007;50(6):31-32.

45. Centers for Disease Control and Prevention (CDC). Lymphogranuloma venereum among men who have sex with men - Netherlands, 2003-2004. MMWR Morb Mortal Wkly Rep. 2004;53(42):985-988.

46. Spaargaren J, Fennema HS, Morré SA, de Vries HJ, Coutinho RA. New lymphogranuloma venereum Chlamydia trachomatis variant. Amsterdam. Emerg Infect Dis. 2005;11(7):1090-1092.

47. Morton AN, Fairley CK, Zaia AM, Chen MY. Anorectal lymphogranuloma venereum in a Melbourne man. Sex Health. 2006;3(3):189-190. 
48. Cusini M, Boneschi V, Arancio L, et al. Lymphogranuloma venereum: the Italian experience. Sex Transm Infect. 2009;85(3):171-172.

49. Bachmann LH, Johnson RE, Cheng H, et al. Nucleic acid amplification tests for diagnosis of Neisseria gonorrhoeae and Chlamydia trachomatis rectal infections. J Clin Microbiol. 2010;48(5):1827-1832.

50. Morré SA, Spaargaren J, Fennema JS, de Vries HJ, Coutinho RA, Peña AS. Real-time polymerase chain reaction to diagnose lymphogranuloma venereum. Emerg Infect Dis. 2005;11(8):1311-1312.

51. Lister NA, Tabrizi SN, Fairley CK, Garland S. Validation of roche COBAS amplicor assay for detection of Chlamydia trachomatis in rectal and pharyngeal specimens by an omp1 PCR assay. J Clin Microbiol. 2004;42(1):239-241.

52. Stamm WE. Lymphogranuloma venereum. In: Holmes KK, Sparling PF, Stamm WE, et al, editors. Sexually Transmitted Diseases. 4th ed. New York: Mc-Graw Hill; 2008:595-606.

53. Centers for Disease Control and Prevention. 2010 Sexually transmitted diseases treatment guidelines. MMWR Morb Mortal Wkly Rep. 2010;59(RR-12):1-110.

54. Bauwens JE, Orlander H, Gomez MP, et al. Epidemic lymphogranuloma venereum during epidemics of crack cocaine use and HIV infection in the Bahamas. Sex Transm Dis. 2002;29(5):255-258.

55. de Vries HJ, Smelov V, Ouburg S, et al. Anal lymphogranuloma venereum infection screening with IgA anti-Chlamydia trachomatis specific major outer membrane protein serology. Sex Transm Dis. 2010;37(12):789-795.

56. van Rooijen MS, Schim van der Loeff MF, Morré SA, van Dam AP, Speksnijder AG, de Vries HJ. Spontaneous pharyngeal Chlamydia trachomatis RNA clearance. A cross-sectional study followed by a cohor study of untreated STI clinic patients in Amsterdam, The Netherlands. Sex Transm Infect. 2014.

57. Verweij SP, Catsburg A, Ouburg S, et al. Lymphogranuloma venereum variant $\mathrm{L} 2 \mathrm{~b}$-specific polymerase chain reaction: insertion used to close an epidemiological gap. Clin Microbiol Infect. 2011;17(11):1727-1730.

58. Stock I, Henrichfreise B. Infections with Chlamidia trachomatis. Med Monatsschr Pharm. 2012;35:209-222.
59. Méchaï F, de Barbeyrac B, Aoun O, Mérens A, Imbert P, Rapp C. Doxycycline failure in lymphogranuloma venereum. Sex Transm Infect. 2010;86(3):278-279.

60. Hocking JS, Kong FY, Timms P, Huston WM, Tabrizi SN. Treatment of rectal chlamydia infection may be more complicated than we originally thought. J Antimicrob Chemother. 2014.

61. Khosropour CM, Dombrowski JC, Barbee LA, Manhart LE, Golden MR. Comparing azithromycin and doxycycline for the treatment of rectal chlamydial infection: a retrospective cohort study. Sex Transm Dis. 2014;41(2):79-85.

62. Smith K, Leyden JJ. Safety of doxycycline and minocycline: a systematic review. Clin Ther. 2005;27(9):132-142.

63. Akcam M, Artan R, Akcam FZ, Yilmaz A. Nail discoloration induced by doxycycline. Pediatr Infect Dis J. 2005;24(9):845-846.

64. Foster JA, Sylvia LM. Doxycycline-induced esophageal ulceration. Ann Pharmacother. 1994;28(10):1185-1187.

65. Tabibian JH, Gutierrez MA. Doxycycline-induced pseudotumor cerebri. South Med J. 2009;102(3):310-311.

66. Periti P, Mazzei T, Mini E, Novelli A. Adverse effects of macrolide antibacterials. Drug Saf. 1993;9(5):346-364.

67. Oberg KC, Bauman JL. QT interval prolongation and torsades de pointes due to erythromycin lactobionate. Pharmacotherapy. 1995; 15(6):687-692.

68. WeeseMayer DE, Yang RJ, Mayer JR, Zaparackas Z. Minocycline and Pseudotumor cerebri: the well-known but well-kept secret. Pediatrics. 2001;108(2):519-520.

69. Macneil M, Haase DA, Tremaine R, Marrie TJ. Fever, lymphadenopathy, eosinophilia, lymphocytosis, hepatitis, and dermatitis: a severe adverse reaction to minocycline. J Am Acad Dermatol. 1997;36(2):347-350.

70. Annan NT, Sullivan AK, Nori A, et al. Rectal chlamydia - a reservoir of undiagnosed infection in men who have sex with men. Sex Transm Infect. 2009;85(3):176-179.
Infection and Drug Resistance

\section{Publish your work in this journal}

Infection and Drug Resistance is an international, peer-reviewed openaccess journal that focuses on the optimal treatment of infection (bacterial, fungal and viral) and the development and institution of preventive strategies to minimize the development and spread of resistance. The journal is specifically concerned with the epidemiology of antibiotic

\section{Dovepress}

resistance and the mechanisms of resistance development and diffusion in both hospitals and the community. The manuscript management system is completely online and includes a very quick and fair peerreview system, which is all easy to use. Visit http://www.dovepress.com/ testimonials.php to read real quotes from published authors. 